\title{
PERANCANGAN CONTROL SYSTEM PENGISIAN FLUIDA OTOMATIS MENGGUNAKAN SENSOR ULTRASONIC SEBAGAI LEVEL AIR \& SENSOR FLOW INDIKASI ALIRAN AIR BERBASIS IOT
}

\author{
Surya Atmajaya ${ }^{1}$, Aswadul Fitri Saiful Rahman ${ }^{2}$, A Asni B ${ }^{3}$ \\ ${ }^{1,2,3}$ Teknik Elektro,Fakultas Teknologi Industri Universitas Balikpapan \\ Jln. Pupuk Raya Gn. Bahagia Balikpapan 76114 INDONESIA
}

\begin{abstract}
The technology applied in some small and medium businesses still applies conventional processes so that the effectiveness of production is less than optimal, on the other hand the technology develops rapidly, especially industrial automation, for example conventional activities where an officer has to monitor and record every water level held in reservoir / tank, this activity can be replaced by an electronic system, which automatically carries out monitoring by reading parameters on the sensor. By creating an automatic reservoir fluid filling system and ESP 8266 based fluid level monitoring integrated with internet network and LCD Touchscreen to facilitate the operator in monitoring fluid levels in the reservoir and fluid filling automatically.

Intisari - Teknologi yang di terapkan pada sebagian usaha kecil menengah masih menerapkan proses konvensional sehingga efektivitas produksi kurang optimal, di sisi lain teknologi berkembang pesat terutama automatisasi di bidang industri, sebagai contoh aktivitas konvensional dimana seorang petugas harus melakukan monitoring dan mencatat tiap ketinggian air yang tertampung di dalam reservoir / tank, aktivitas ini dapat digantikan oleh sistem elektronik, yang secara otomatis melakukan monitoring dengan membaca parameter pada sensor. Dengan membuat sebuah sistem pengisian fluida reservoir secara otomatis dan monitoring ketinggian fluida yang berbasis ESP 8266 yang terintergrasi dengan jaringan internet dan LCD Touchscreen untuk mempermudah operator dalam monitoring ketinggian fluida pada reservoir dan pengisian fluida secara otomatis.
\end{abstract}

Kata Kunci : Reservoir, fluida, LCD Touchscreen, Level Ketinggian Air, Sensor Ultrasonic, ESP 8266

\section{PENDAhUluan}

Teknologi yang di terapkan pada sebagian usaha kecil menengah masih menerapkan proses konvensional sehingga efektivitas produksi kurang optimal, di sisi lain teknologi berkembang pesat terutama automatisasi di bidang industri, sebagai contoh aktivitas konvensional dimana seorang petugas harus melakukan monitoring dan mencatat tiap ketinggian air yang tertampung di dalam reservoir/tank, aktivitas ini dapat digantikan oleh sistem elektronis, yang secara otomatis melakukan monitoring dengan membaca parameter pada sensor.

Arduino Nano dapat menjadi basis dalam kinerja sebuah perancangan Otomatis input dan output melalui masing-masing portnya sehingga dapat menjadi solusi untuk membantu meringankan kinerja bagi petugas dalam pengontrolan pengisian fluida indikasi aliran fluida dan monitoring fluida reservoir jarak jauh menggunakan sambungan wireless agar mempermudah operasional [1].

\section{TINJAUAN PUSTAKA}

Berikut detail dari teori yang berkaitan dengan alat makan dan minum ayam secara otomatis sebagai landasan dalam pembuatan alat dan penyusunan laporan :

\section{A. Penelitian Yang Relevan}

Penelitian tentang sensor ultrasonik telah banyak dilakukan oleh peneliti-peneliti sebelumnya diantaranya oleh Githa, Dwi Putra Swastawan, Wayan Eddy dalam penelitiannya yang berjudul Sistem Pengaman Parkir dengan Visualisasi Jarak Menggunakan Sensor PING dan LCD. Hasil yang diperoleh dari penelitian ini adalah berupa alat yang dapat mendeteksi adanya benda penghalang yang berada disekitar mobil [3].

Skripsi Slamet Hani tentang Sensor Ultrasonik Sebagai Pemantau Kecepatan Kendaraan Bermotor. Desain alat pemantau kecepatan ini terdiri dari dua sensor, pertama mengukur jarak pantul dari sensor ultrasonik kurang dari batas maksimal pemantaun. Sensor akan mulai menghitung waktu dan waktu akan berhenti saat sensor kedua mendapatkan pantulan. Besar nilai kecepatan yang didapat adalah hasil bagi antara jarak kedua sensor dengan waktu pantul antara dua sensor. Besarnya nilai kecepatan akan ditampilkan melalui LCD [4].

Berdasarkan hasil tersebut, dapat disimpulkan bahwa sensor ultrasonik valid dan dapat digunakan sebagai perangkat pengukur kecepatan aliran udara dalam pipa. Berdasarkan penelitian tersebut, sensor ultrasonik baik digunakan untuk mengukur jarak suatu benda yang bersifat padat, cair, dan gas. Oleh karena itu, penulis akan melakukan penelitian tentang automatic water level control berbasis mikrocontroller dengan sensor ultrasonik. Dengan adanya penelitian ini diharapkan tidak ada lagi tandon penampung air yang meluap atau kosong dikarenakan kurangnya pengontrolan.

\section{B. IOT (Internet Of Things)}

Menurut Wikipedia, Internet of Things atau dikenal juga dengan singkatan IoT, merupakan sebuah konsep yang bertujuan untuk memperluas manfaat dari konektivitas internet yang tersambung secara terus-menerus. Adapun kemampuan seperti berbagi data, remote control, dan sebagainya, termasuk juga pada benda di dunia 
nyata. Contohnya bahan pangan, elektronik, koleksi, peralatan apa saja, termasuk benda hidup yang semuanya tersambung ke jaringan lokal dan global melalui sensor yang tertanam dan selalu aktif [6].

\section{Sensor Ultrasonik}

Sensor ultrasonik adalah sensor yang bekerja berdasarkan prinsip pantulan gelombang suara dan digunakan untuk mendeteksi 7 keberadaan suatu objek tertentu di depannya, frekuensi kerjanya pada daerah di atas gelombang suara dari $40 \mathrm{KHz}$ hingga $400 \mathrm{KHz}$. Sensor ultrasonik terdiri dari dari dua unit, yaitu unit pemancar dan unit penerima. Struktur unit pemancar dan penerima sangatlah sederhana, sebuah kristal piezoelectric dihubungkan dengan mekanik jangkar dan hanya dihubungkan dengan diafragma penggetar. Tegangan bolak-balik yang memiliki frekuensi kerja $40 \mathrm{KHz}-400 \mathrm{KHz}$ diberikan pada plat logam.

\section{Modul Esp 8266}

Modul ESP8266 adalah sebuah komponen chip terintegrasi yang didesain untuk keperluan dunia masa kini yang serba tersambung. Chip ini menawarkan solusi networking Wi-Fi yang lengkap dan menyatu, yang dapat digunakan sebagai penyedia aplikasi atau untuk memisahkan semua fungsi networking Wi-Fi ke pemproses aplikasi lainnya.

\section{E. LCD Nextion Touch Screen 2,4 inch}

LCD Nextion adalah display atau user interface yang digunakan sebagai indikator atau monitoring alat yang akan dibuat. LCD Nextion HMI ini dilengkapi dengan bantuan software Nextion Editor berbasis GUI WYSIWYG (What You See Is What You Get) dengan platform Microsoft Windows yang dapat di download gratis pada situs resmi produsen nya (ITEAD). Dengan besar layar 2,4 inch, modul touch screen ini bisa menampilkan banyak data dan interface dengan sangat bagus

\section{F. Flow Sensor}

Flow meter adalah alat untuk mengukur jumlah atau laju aliran air dari suatu fluida yang mengalir dalam pipa atau sambungan terbuka. Alat ini terdiri dari primary device, yang disebut sebagai alat utama dan secondary device (alat bantu sekunder). Flowmeter umunya terdiri dari dua bagian, yaitu alat utama dan alat bantu sekunder. Alat utama menghasilkan suatu signal yang merespon terhadap aliran karena laju aliran tersebut telah terganggu.

\section{G. Relay}

Relay adalah saklar elektro-magnetik yang menggunakan tegangan DC rendah untuk menghidupkan dan mematikan suatu alat atau sistem yang terhubung dengan tegangan DC yang tinggi atau tegangan AC. Susunan relay yang paling sederhana terdiri atas kumparan kawat penghantar yang dugulung pada inti besi [16].

\section{H. Pompa Aquarium}

Pompa adalah mesin atau peralatan mekanis yang digunakan untuk menaikkan cairan dari dataran rendah ke dataran tinggi atau untuk mengalirkan cairan dari daerah bertekanan rendah ke daerah yang bertekanan tinggi dan juga sebagai penguat laju aliran pada suatu sistem jaringan perpipaan [18].

\section{METODE PENELITIAN}

Pada penelitian ini, penulis melakukan penelitian di halaman Kampus Universitas Balikpapan, yang akan dilakukan pengamatan dan pengambilan data dilaksanakan pada tanggal 15 Januari sampai dengan tanggal 15 juli 2019.

\section{A. Diagram Alir Penelitian}

Diagram penelitian disusun berdasarkan proses jalannya penelitian mulai dari persiapan penelitian, kajian literature, instrument penelitian, pengumpulan data hingga pada penyusunan laporan termasuk persiapan perancangan alat.

Didalam alir penelitian dimulai dengan studi literature untuk mengumpulkan materi-materi berkaitan dengan penelitian yang akan dilakukan. Dengan studi literatur yang telah dikumpulkan maka penulis selanjutnya mempelajari konsep dasar dari penelitian yang akan dilakukan dan dilakukan juga dengan instrument data pendukung termasuk alat dan peralatan. Pengumpulan data pendukung diperlukan untuk mengumpulkan data pendukung pada alat peralatan yang akan digunakan pada rangkaian.

Setalah data yang digunakan telah siap, penulis masuk kedalam sesi perancangan alat dan instalsi alat.

Diagram alir penelitian dapat ditunjukkan dalam gambar 3.1 agar mempermudah pemahaman penelitian.

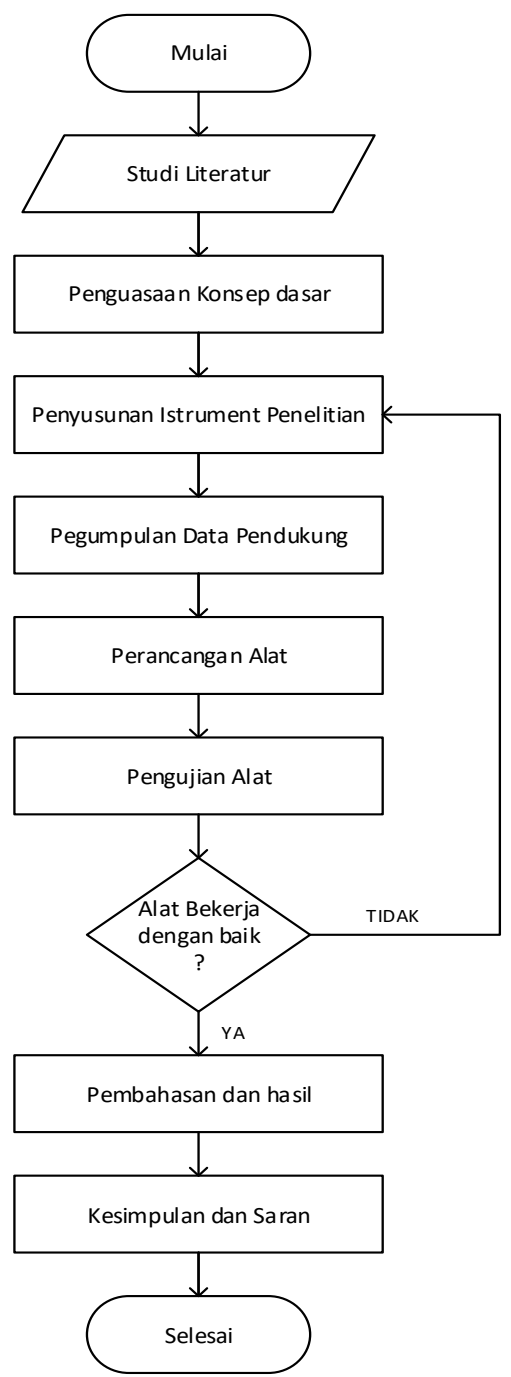

Gambar 1 Diagram Alir Penelitian 


\section{B. Diagram Alir Perancangan Alat}

Didalam perancangan alat, penulis menyusun diagram alir seperti yang ditunjukkan pada gambar 3.2

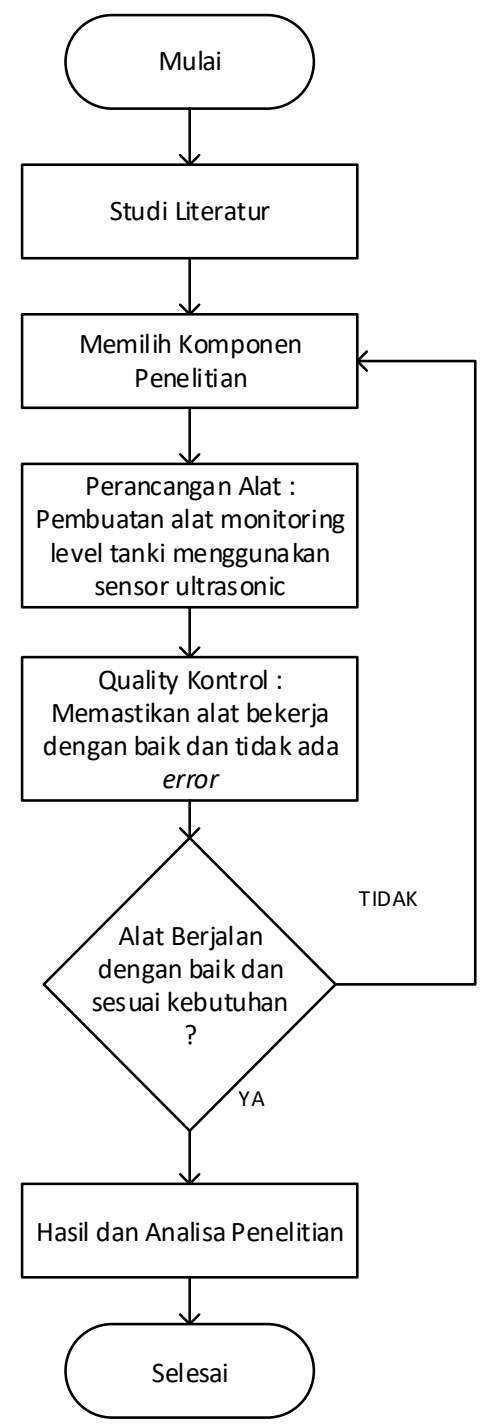

Gambar .2 Diagram Alir Perancangan

Didalam gambar .2 perancangan tersebut terlihat alur perancangan alat penelitian. Didalam perancangan awal dilakukan pemilihan komponen dan dilakukan perancangan alat yaitu menentukan skema rangkaian dan penyusunan koding setelah perancangan alat selesai maka dilakukan quality qontrol untuk mengetahui apakah alat berjalan dengan baik atau tidak, jika alat tidak berjalan dengan baik maka dilakukan pemeriksaan komponen ulang untuk memastikan. Komponen mana yang tidak sesuai dan jika alat berjalan dengan baik maka proses hasil analisis dan penelitian telah selesai.

\section{HASIL DAN PEMBAHASAN}

Berikut ini adalah proses hasil dan pembahasan dari penelitian ini : A. Implementasi Alat

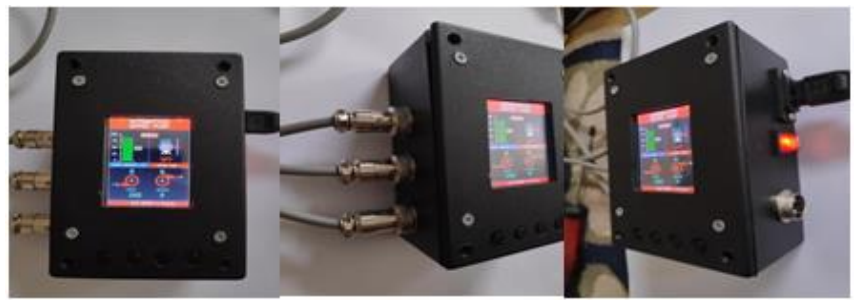

Gambar 3 Tampak Depan dan Sisi Samping alat monitoring level

Penerapan untuk perancangan alat monitoring level reservoir otomatis dengan sensor dan berbasis mikrokontroller arduino ini menggunakan beberapa komponen utama. Yaitu, arduino nano itu sendiri sebagai antar muka untuk Nextion LCD 2.4 inch, dan ESP 8266 sebagai input sensor dan output relay, serta berfungsi untuk koneksi penghubung alat dengan server dan sensor ultrasonik yang digunakan sebagai mendeteksi adanya fluida dalam reservoir, dan flow sensor berfungsi untuk mengetahui adanya aliran fluida untuk input pada reservoir dan output reservoir .dan menggunakan control relay yang berfungsi sebagi pemutus arus pompa.

B. Cara Kerja Alat

Dalam tahap ini, penulis akan menjelaskan cara mengoperasikan alat dalam dua mode :

1. Mode Manual

1. Pastikan alat terhubung dengan jarinagn internet. Ditandai dengan tampilnya total aliran pada display utama.

2. Setelah jaringan internet telah terhubung, tekan tombol setup sampai muncul tampilan "MANU" pada display.

3. Tekan tombol ON/OFF, untuk mengetahui kondisi pompa hidup atau mati dengan melihat pada tampilan utama "WATER PUMP" maka kondisi pompa akan berubah saat menekan tombol ON/OFF.

4. Jika selesai mengoperasikan alat dengan mode "MANUAL", jangan lupa mengembalikan pada posisi "AUTO".

\section{Mode Otomatis Dengan IOT}

1. Untuk Automatis dari handphone dengan cara mengklik tombol auto pada handphone, maka alat akan beroperasi pada mode automatis dan jika kondisi minimum level tercapai maka pompa secara automatis akan menyala dan jika kondisi maksimal terpenuhi maka pompa akan mati.

2. Untuk menonaktifkan mode auto yang tadinya di aktifkan melalui smartphone atau laptop dan ingin kembali kepada mode manual. Klik tombol "manual" pada smartphone atau laptop. dan tombol on off pompa manual dapat digunakan. Jika penggunaan mode manual telah selesai digunakan kembalikan system ke dalam mode "Auto".

\section{Spesifikasi Sistem}

Dalam penerapan control system pengisian fluida reservoir secara otomatis yang telah dirancang, maka diperlukan pengujian terhadap sistem yang dikerjakan.

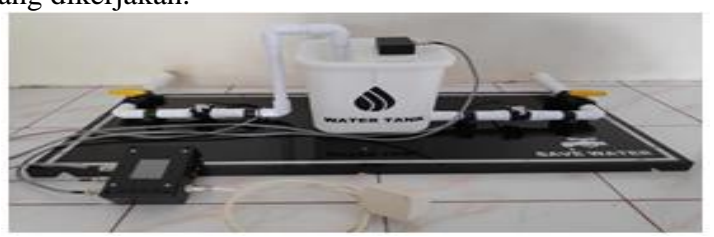

Gambar 4. Rangkaian Alat Keseluruhan. 
Penjelasan dari rangkaian alat pada gambar di atas sebagai berikut :

1. Arduino Nano, pada perancangan alat ini Arduino Nano merupakan otak dalam mengendalikan tampilan pada LCD Touch Screen dan relay. diprogram melalui software Arduino IDE yang kemudian diupload ke Arduino Nano untuk menjalankan program yang penulis buat.

2. ESP 8266 merupakan proses utama pada alat ini yang berfungsi untuk mengontrol sensor dan output relay serta koneksi internet untuk menjalankan program di web.

3. Sensor Ultrasonik, pada alat ini sebagai pengukur level fluida pada reservoir.

4. Relay, pada perancangan alat ini berfungsi sebagai saklar yang menghidupkan dan mematikan pompa.

5. Sensor Flow berfungsi sebagai indicator jika adanya aliran fluida pada input dan output pada reservoir.

6. Pompa air, pada perancangan alat ini berfungsi untuk mengisi fluida pada reservoir.

\section{Pengujian Alat}

Pengujian sistem berguna sebagai menguji coba dan mengetahui apakah alat sudah bekerja sesuai dengan spesifikasi perencanaan yang telah direncanakan sebelumnya. Pengujian ini dilakukan untuk mengetahui kerja perangkat keras pada masing masing rangkaian dapat bekerja dengan baik antara lain pengujian rangkaian Arduino Nano dengan LCD Nextion 2.4 inch dan relay, pengujian rangkaian ESP 8266 dengan sensor ultrasonic, dan sensor flow. Kemudian data hasil pengujian yang diperoleh nantinya akan dibahas untuk dijadikan dalam pengambilan kesimpulan.

Untuk megatur parameter minimal level, maksimal level dan kalibrasi reservoir yang akan dipasang alat ini dapat dilakukan dengan cara,

1. Menyentuh pojok kanan atas layar pada LCD selama 3 detik.

2. Setelah menyentuh pojok kanan atas layar, maka akan muncul tampilan seperti berikut.

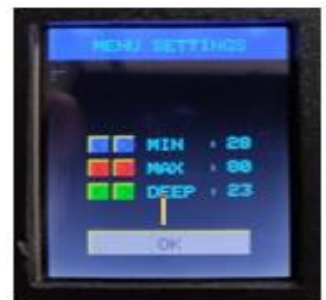

Gambar 5 Tampilan menu setting LCD pada alat.

3. MIN berfungsi untuk memasukan nilai minimal pembacaan level pada sensor ultrasonic. Jika nilai tercapai maka relay akan hidup.

4. MAX berfungsi untuk memasukan nilai maksimal pembacaan level pada sensor ultrasonic. Jika nilai tercapai maka relay akan mati.

5. DEEP berfungsi untuk memasukan nilai dalam satuan $\mathrm{cm}$ atau mengkalibrasi tinggi dari reservoir yang akan dipasang alat dari dasar sampai batas sensor ultrasonic. Dalam miniatur ini dimasukan nilai DEEP sebesar 23.

6. Jika selesai memasukan nilai parameter maka sentuh OK.

7. Maka parameter MAX, MIN dan DEEP akan otomatis berjalan mengikuti settingan parameter yang telah dimasukan.
Tabel 1 Tabel Perintah Serial Pada Arduino IDE

\begin{tabular}{|c|l|}
\hline Command & \multicolumn{1}{|c|}{ Fungsi } \\
\hline SSID & Berfungsi untuk memasukan User Name Wifi \\
\hline PASSWORD & Berfungsi untuk memasukan Password wifi \\
\hline MAX & $\begin{array}{l}\text { Berfungsi untuk memasukan nilai maksimal } \\
\text { kondisi pompa OFF }\end{array}$ \\
\hline MIN & $\begin{array}{l}\text { Berfungsi uniuk memasukan nilai minimal } \\
\text { kondisi pompa ON }\end{array}$ \\
\hline DEEP & $\begin{array}{l}\text { Berfungsi untuk kalibrasi ketinggian media } \\
\text { yang akan dipasang sensor ketinggian }\end{array}$ \\
\hline
\end{tabular}

E. Pengujian Sensor Ultrasonic

Pengujian rangkaian terhadap sensor ultrasonic, yaitu pengujian untuk pergerakkan jarak atau level yang ditampilkan pada LCD dalam bentuk bar vertical.

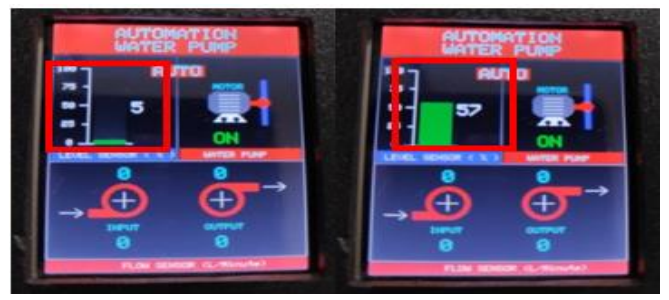

Gambar 6 Tampilan pembacaan sensor ultrasonic pada LCD.

Berikut tabel pengujian tombol dengan Sensor.

Tabel 2 Tabel Pengujian Tombol dengan Sensor.

\begin{tabular}{|c|c|c|c|}
\hline NO & Mode & Kondisi Sensor & Hasil \\
\hline 1 & MANUAL & Tidak mengikuti & Motor Hidup Manual \\
\hline 2 & AUTO & Mengikuti & Motor Hidup Automatis \\
\hline
\end{tabular}

F. Pengujian sensor Flow dengan Display LCD

pengujian flow sensor inpu dan output dengan LCD. Dimana dalam pengujian ini berguna untuk mengetahui apakah sensor berfungsi jika terdapat aliran pada input dan output jalur pemipaan pada reservoir.

Ditampilkan dengan debit air satuan Liter per menit dan total debit dari input dan output flow sensor tersebut.
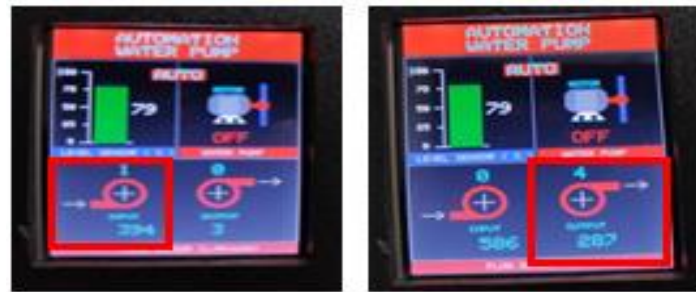

Gambar 7 Tampilan flow sensor input dan Output pada LCD.

Berikut tabel pengujian sensor aliran.

Tabel 3 Tabel Pengujian Sensor Aliran

\begin{tabular}{|c|c|c|c|}
\hline Sensor & Status & Status LCD & Status IOT \\
\hline Flow 1 & Ada Aliran & Terbaca & Terbaca \\
\hline Flow 1 & Tidak Ada Aliran & Tidak terbaca & Tidak Terbaca \\
\hline Flow 2 & Ada Aliran & Terbaca & Terbaca \\
\hline Flow 2 & Tidak Ada Aliran & Tidak terbaca & Tidak Terbaca \\
\hline
\end{tabular}


G. Pengujian Relay dengan Display LCD

Pada tahap ini melakukan proses pengujian relay terhadap LCD relay ini berfungsi jika kondisi parameter MIN dan MAX terpenuhi, saat level berada pada posisi minimal sesuai dengan nilai yang telah dimasukan pada menu setting maka relay aktif secara otomatis dan akan mati jika nilai parameter maksimal telah tercapai. Dan dapat diakses dengan cara mode manual
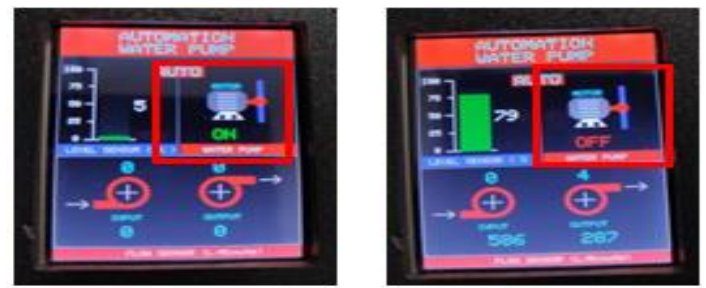

Gambar 8 Kondisi Motor ON dan OFF pada LCD.

Berikut tabel Pengujian tombol dengan mode MANUAL dan AUTO

Tabel 4 Pengujian tombol dengan mode MANUAL dan AUTO

\begin{tabular}{|c|c|c|c|}
\hline NO & MODE & Tombol ON & Tombol OFF \\
\hline 1 & Manual & Berfungsi & Berfungsi \\
\hline 2 & Auto & Tidak Berfungsi & Tidak Berfungsi \\
\hline
\end{tabular}

H. Pengujian Alat Dengan Tampilan WEB Pada laptop atau komputer

Pada tahap ini dilakukan pengujian monitoring alat dengan koneksi internet dan ditampilkan pada web Localhost:8000, maka parameter dari level, flow in, flow out dan kodisi motor akan terbaca pada web tersebut. Ketik pada seacrh dan ketikan "Localhost:8000" kemudian tekan enter maka akan muncul tampilan web.

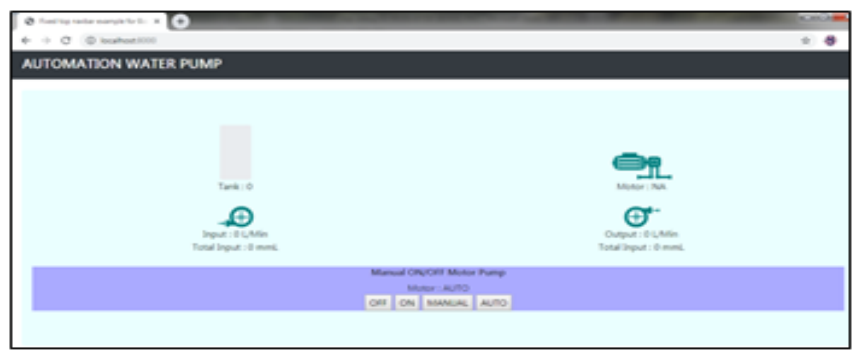

Gambar 9 Monitoring Level menggunakan IOT

Tabel 5 Pengujian koneksi alat dengan Laptop

\begin{tabular}{|c|c|c|}
\hline Lokasi Alat & Lokasi Pengguna & Koneksi \\
\hline Rumah & Rumah & Terhubung \\
\hline Rumah & Luar Daerah & Terhubung \\
\hline Rumah & Luar Pulau & Terhubung \\
\hline
\end{tabular}

\section{Pengujian Alat Dengan Smart Phone}

Pada tahap ini dilakukan pengujian monitoring alat dengan koneksi internet dan ditampilkan pada web browser, maka parameter dari level, flow in, flow out dan kodisi motor akan terbaca pada web tersebut. di tampilan awal aplikasi kemudian pilih "MATI" dan tombol akan otomatis menjadi "AKTIF' klik link yang telah tersedia Maka secara otomatis akan mengarahkan ke web monitoring.

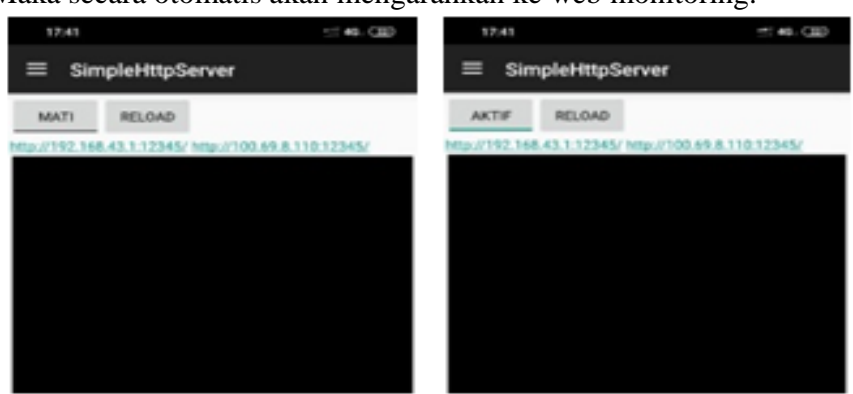

Gambar 10 Menu Utama pada aplikasi SimpleHttpServer.

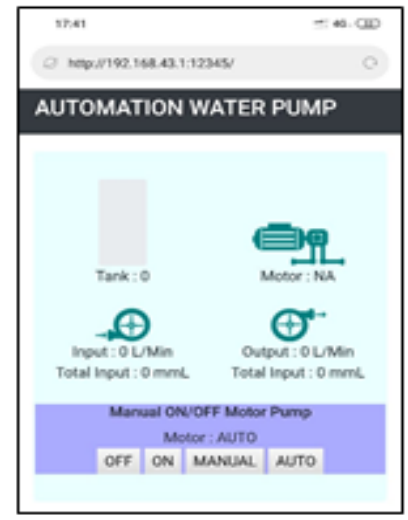

Gambar 11 Tampilan Monitoring pada browser smartphone

\section{KESIMPULAN}

Setelah selesai melakukan tahap perancangan dan pembuatan sistem yang kemudian dilanjutkan dengan tahap implementasi dan pengujian alat maka dapat diambil kesimpulan bahwa peneliti berhasil membuat perancangan control system pengisian fluida reservoir secara otomatis menggunakan sensor ultrasonic sebagai level air \& sensor flow sebagai indikasi aliran air berbasis iot esp 8266, alat ini dapat berfungsi secara otomatis sesuai dengan parameter yang telah diisi, dan dapat diakses dalam 2 mode, Auto dan Manual serta alat ini juga dapat dimonitoring melalui web baik menggunakan laptop maupun smartphone.

\section{REFERENSI}

[1] E. N. Diansyah, "Rancang Bangun Alat Sistem Monitoring Volume dan Kejernihan Air Pada Tangki Berbasis LabView dengan Kontroller NI MYRIO," Coding J. Komput. dan Apl. Untan, 2015

[2] D. P. Githa and W. E. Swastawan, "Sistem Pengaman Parkir dengan Visualisasi Jarak Menggunakan Sensor PING dan LCD," J. Nas. Pendidik. Tek. Inform., vol. 3, pp. 1-5, 2014.

[3] S. Hani, "Sensor Ultrasonik SRF05 sebagai Memantau Kecepatan Kendaraan Bermotor," J. Teknol., vol. 3, no. 2, pp. 120 $128,2010$.

[4] Wikipedia Contributors, "Internet of Things - Wikipedia." 2019. [Accessed Sunday. Juny. 02, 2019]

[5] “SPDT 1-Amp 12V Relay Switch.”@ radioshack.com [Accessed thursday. March. 07, 2019]

[6] Sentral Pompa, "Resun SP-2500 Pompa Celup for Aquarium.”@sentralpompa.com 